\title{
IMPRENSA E DISCURSOS SOBRE A LEITURA: REPRESENTAÇÕES DOS PRESIDENTES FHC, LULA E DILMA COMO LEITORES
}

\section{Luzmara Curcino ${ }^{\text {ii }}$}

Resumo: Em sociedades hierarquizadas como a brasileira certas representações culturais de prestígio são empregadas para a justificação e naturalização dessas hierarquias. As representações da leitura são um exemplo. Por se tratar de uma prática que goza de um importante valor simbólico, as referências a ela podem contribuir para a reprodução de privilégios, para a imposição de estigmas e manutenção das divisões sociais. Não sem razão, ela é aludida em textos da mídia impressa nacional como um atributo não negligenciável no campo da política. Isso se avoluma a partir de 1989, quando um outsider cultural se apresentou como candidato às eleições presidenciais. Neste artigo, nosso objetivo é analisar como foram mobilizados certos discursos sobre a leitura em textos da imprensa para a construção e qualificação dos perfis dos presidentes Fernando Henrique Cardoso, Luiz Inácio Lula da Silva e Dilma Rousseff. Para tanto, nos valemos de princípios teóricos da Análise de discurso, da História da leitura e da Sociologia cultural.

Palavras-chave: Discursos sobre a leitura. Política brasileira. Imprensa nacional. Hierarquias culturais.

\begin{abstract}
In hierarchical societies such as Brazil, certain cultural representations are used to justify and naturalize these social divisions. The representations of reading are an example. Considering that this practice has an important symbolic value in our society, references to it can contribute to the reproduction of privileges, to the imposition of stigmata and maintenance of social divisions. Not without reason, it is alluded to in national press media as a significant attribute in the field of politics, especially since 1989 , when a cultural outsider presented herself as a candidate for presidential elections. In this article, our objective is to analyze how some discourses about reading are been mobilized in the construction of the profiles of the presidents Fernando Henrique Cardoso, Luiz Inácio Lula da Silva and Dilma Rousseff. For this purpose, the analysis will theoretically be based on the principles of discourse analysis, reading history and cultural sociology.
\end{abstract}

Keywords: Discourses about reading. Brazilian politicians. Brazilian press. Cultural hierarchies.

\footnotetext{
'Este texto apresenta resultados da pesquisa "Divisões sociais dos leitores no Brasil: uma análise de discursos da mídia sobre as práticas de leitura de políticos brasileiros" (com apoio do CNPq bolsa PDS - 104991/2016-0), desenvolvida sob a supervisão de Sírio Possenti (UNICAMP).

ii Professora do Departamento de Letras e do Programa de Pós-Graduação em Linguística da Universidade Federal de São Carlos (UFSCar), Brasil.Email: luzcf@hotmail.com.
} 
EID\&A - Revista Eletrônica de Estudos Integrados em Discurso e Argumentação, Ilhéus, n. 16 esp. "Discurso e argumentação na política latino-americana, set.2018.

\section{Introdução}

Há certas competências e qualidades consideradas necessárias ou exigidas institucionalmente para a atuação política. Por isso, elas são comumente enunciadas e reiteradas em processos de disputa eleitoral ou durante o exercício de um cargo representativo. Outras, menos comuns e 'mais genéricas', não ligadas estritamente ao campo em questão e às suas práticas, podem ser evocadas e exploradas na constituição da imagem pública de políticos.

Na história recente da política brasileira, a leitura é um exemplo de prática 'paralela' ou 'acessória' à política que nas últimas décadas foi mais frequentemente convocada. Isso se explica, em grande parte, em função da participação de um outsider cultural na disputa eleitoral à presidência da república'. Desde então, ampliou-se o número e a variedade de textos - da mídia tradicional aos blogs pessoais - que trazem à baila alguma menção relativa ao perfil letrado, e em específico ao perfil leitor, de políticos brasileiros. São textos bastante distintos tematicamente, cujas referências à leitura, em sua grande maioria, limitam-se a rápidas menções, sem necessário vínculo direto com o assunto principal que abordam. Foram produzidos por jornalistas e formadores de opinião de vários matizes político-partidários, o que não impede que essas referências compartilhem formas de representação similares acerca do leitor e se ancorem em discursos comuns sobre a leitura.

De modo a refletir sobre a emergência desse discurso no cenário contemporâneo da política brasileira, neste artigo, analisamos como são mobilizadas certas representações da leitura na construção do perfil dos presidentes Fernando Henrique Cardoso, Luiz Inácio Lula da Silva e Dilma Rousseff. Subsidiados teoricamente por princípios da Análise de discurso, da História da leitura e da Sociologia cultural, buscamos depreender certas formas de representação dessa prática que, há muito e de forma variável, sustentam dizeres e crenças sobre o que é ser leitor, fomentam certas práticas em detrimento de outras e outorgam, por extensão, a certos sujeitos e a suas ações um grau de autoridade, atuando assim como um trunfo não negligenciável em campos como o da política brasileira.

\footnotetext{
${ }^{1}$ Todos os presidentes do Brasil, até a eleição de Lula, cursaram ensino superior, alguns no âmbito da escola militar. Entre esses bacharéis, vários publicaram livros, como Getúlio Vargas, José Sarney e Fernando Henrique Cardoso, tornando-se inclusive membros da Academia Brasileira de Letras. Diferentemente dos demais, Lula concluiu institucionalmente formação escolar básica e técnica, tendo sido operário do setor de metalurgia e sindicalista.
} 
EID\&A - Revista Eletrônica de Estudos Integrados em Discurso e Argumentação, Ilhéus, n. 16 esp. "Discurso e argumentação na política latino-americana, set.2018.

\section{Leitura e Política: do 'capital cultural’ e de seu poder de legitimação}

Os discursos, e consequentemente as representações dos sujeitos, dos objetos e das práticas, atuam sob a forma de dispositivos de poder, de saber e de sujeição, segundo Foucault (1996), de modo a constituir o que somos, fazemos e sabemos e a instituir o valor de verdade das práticas, dizeres e crenças em um dado tempo e em uma dada sociedade. Isso nos exige refletir sobre quais são os discursos que sustentam o que pensamos de nós e dos outros; como são produzidos; como circulam; como adquirem valor de verdade; quais são suas formas de institucionalização responsáveis por suas diferentes durações.

O relativo consenso em torno do prestígio que a prática de leitura dispõe atualmente entre nós não é recente e resulta de um processo histórico discursivo peculiar, ao longo do qual se constituíram formas de valoração e de idealização de certos usos e objetos em consonância com o prestígio dos sujeitos que deles se valem. Essa lógica seletiva e hierárquica participa da construção de uma espécie de 'fantasia' coletiva, segundo Bayard (2007), do que seja ler e do que é ser leitor, e que nos impõe uma régua um tanto simplista com a qual avaliamos e somos avaliados em relação a essa prática.

Grosso modo, o discurso sobre a leitura define um 'ser leitor ideal' que, como em toda idealização, pode ser reconhecido pelo tom assertivo e hiperbólico adotado no modo de caracterizar esse perfil. É leitor quem lê e possui livros; quem lê sempre, muito e os textos em sua totalidade; quem lê em silêncio e solitariamente; quem dispõe de biblioteca ou as frequenta. É o grau de coincidência entre nossas práticas e essas que são valorizadas culturalmente que faz com que nos identifiquemos e nos reconheçamos, assim como aos outros, como leitores ou como não-leitores, com toda a carga valorativa implicada nesse processo de identificação a essas representações.

Diferentemente de mero reflexo do real, essas representações, segundo Roger Chartier (2011, p.27), não devem ser concebidas como "simples imagens, verídicas ou enganosas, do mundo social". Elas

[...] não são de forma alguma discursos neutros: produzem estratégias e práticas (sociais, escolares, políticas) que tendem a impor uma autoridade à custa de outros, por elas menosprezados, a legitimar um projeto reformador ou a justificar, para os próprios indivíduos, as suas escolhas e condutas. [...] As lutas de representações têm tanta importância como as lutas econômicas para compreender os mecanismos pelos quais um grupo impõe, ou tenta impor, a sua 
EID\&A - Revista Eletrônica de Estudos Integrados em Discurso e Argumentação, Ilhéus, n. 16 esp. "Discurso e argumentação na política latino-americana, set.2018.

concepção do mundo social, os valores que são os seus, e o seu domínio. (CHARTIER, 1990, p.17)

Assim, o modo como concebemos uma dada prática, a forma como a enunciamos e a maneira como a exercemos não são alheios, antes o contrário, às representações que circulam socialmente com estatuto de verdade. No que diz respeito às representações ligadas ao 'capital cultural', como é o caso da leitura, elas desempenham papel de elemento-chave na lógica de 'distinção' dos sujeitos e de 'reprodução' duradoura das hierarquias sociais e culturais que os distinguem, assim como são usadas para justificar o acesso regrado a instâncias de poder, como a política. Afinal, além de sustentar essas hierarquias, o 'capital cultural' de prestígio, como demonstrou Pierre Bourdieu (2007), também as justifica, legitima, naturaliza e universaliza.

Em sociedades como a brasileira, em que as divisões sociais são mais sensíveis pelas proporções da desigualdade econômica, pela fragilidade das instituições e dos serviços públicos, pela relativização do direito à cidadania em função da classe socioeconômica dos sujeitos, os subterfúgios para a manutenção desse cenário precisam ser discretos, bastante convincentes e eficazes. Por isso, é preciso recorrer a vários e insuspeitos mecanismos de validação do poder, afinal, numa democracia formal, é preciso parecer - ainda que a realidade mostre o contrário - que o acesso ao poder é de fato democrático, que é fruto exclusivamente de decisão pública, que advém de escolha da maioria, logo, é legítimo.

Um importante mecanismo de legitimação do poder político é o da legitimação cultural de seus atores. Essa blindagem cultural depende da invisibilidade de seu processo de distribuição desigual: em geral, os detentores dos bens culturais e simbólicos de prestígio são também os árbitros que os avaliam e hierarquizam como tal, produzindo um reconhecimento consensual desse valor e dessa hierarquia. São também, consequentemente, aqueles que usufruem dos benefícios desse consenso, uma vez que contam com o pressuposto de que dominam essa cultura. Por extensão, são os mesmos a se beneficiarem da crença na importância desse domínio cultural como condição sine qua non para o exercício da política.

\footnotetext{
${ }^{2}$ Tal como o define Pierre Bourdieu (2007), o 'capital cultural' diz respeito ao tipo e quantidade de informação/formação que se tem Acesso em: função de sua origem (social, econômica, cultural, histórica), ao qual se atribui valor específico com poder distintivo dos sujeitos.
} 
EID\&A - Revista Eletrônica de Estudos Integrados em Discurso e Argumentação, Ilhéus, n. 16 esp. "Discurso e argumentação na política latino-americana, set.2018.

Dentre as formas mais reconhecíveis de ostentação desse 'capital cultural', o livro é um símbolo por excelência. Em diferentes épocas e em diversos regimes, o livro encarnou a representação do "poder esclarecido" (CHARTIER, 1999, p. 84). Assim, em sua dimensão simbólica, o livro e a leitura têm participado da política. No contexto da política brasileira, sua evocação ganhou fôlego em especial de 1994 para cá, quando um intelectual disputou as eleições presidenciais com um operário.

\section{FHC, o leitor ideal}

Fernando Henrique Cardoso, presidente por dois mandatos (1995-1998 / 1999-2002), entre os últimos presidentes do Brasil é aquele que mais regularmente é representado como leitor. Isso pode ser explicado por duas razões: pelo reconhecimento público de sua formação e atuação como intelectual; e pelo contraste que era preciso estabelecer entre seu perfil e o de Lula, seu principal concorrente nas duas eleições à presidência (1994 e 1998).

São vários os textos que recorrem ao livro como símbolo na representação da condição leitora de FHC. Os enunciadores nesses textos se valem de uma série de imagens temática e estruturalmente muito semelhantes. Predomina o gênero fotográfico, com imagem posada e dirigida, cuja composição conta exclusivamente com o presidente, sempre no centro e em primeiro plano, por vezes com um livro na mão, mas invariavelmente com uma estante de livros ao fundo. O efeito geral objetivado nessas imagens é o de afirmar a referencialidade do que é retratado, do 'ser assim' do representado.

Ademais, a maioria dos textos em que figuram imagens que representam o presidente como leitor, em sua composição verbal, abordam outros temas. Essa desvinculação temática entre a imagem e o que é enunciado verbalmente nos demais textos é um indício bastante interessante da força e naturalização, junto a esses meios midiáticos, de um protocolo de representação do presidente como leitor. A constituição desse protocolo resulta do funcionamento próprio a todo discurso e o modo como ele se inscreve em uma dada memória discursiva ${ }^{3}$, responsável pela evocação de

\footnotetext{
${ }^{3}$ A “memória discursiva”, segundo Jean-Jacques Courtine (1999), tem por princípio aliar o que é dito à sua condição de acontecimento na história e restituir a essa materialidade do enunciado sua relação complexa de atualização de diferentes temporalidades.
} 
EID\&A - Revista Eletrônica de Estudos Integrados em Discurso e Argumentação, Ilhéus, n. 16 esp. "Discurso e argumentação na política latino-americana, set.2018.

outros enunciados, cuja duração é regulada por um regime singular de repetição e apagamento.

Governantes retratados diante de bibliotecas ou com livros à mão não são uma invenção de hoje, nem uma especificidade tupiniquim. Na fotografia oficial de seu segundo mandato, FHC é representado diante de livros na biblioteca do Palácio da Alvorada. Ele é o primeiro presidente a quebrar a tradição das fotografias presidenciais que, em geral, adotavam um fundo neutro. Ele é o único no Brasil ${ }^{4}$, até hoje, que se valeu desse símbolo letrado. Essa regularidade em sua representação se manifesta ainda verbalmente, de modo diverso e em vários textos:

O ex-presidente Fernando Henrique Cardoso, de férias em Paris, tem-se dedicado mais a exposições de arte, leituras e compras de supermercado do que à política [...]. Em menos de uma semana, FHC visitou duas exposições: do francês Francis Picabia e do italiano Amadeo Modigliani. Lê os jornais "Le Figaro", "Le Monde" e "International Herald Tribune", além de um clipping de notícias brasileiras enviado pela embaixada. "Mas não estou com ansiedade de ficar lendo sobre o Brasil. É preciso dar tempo ao tempo. Não quero ficar me preocupando e me envolvendo com as coisas brasileiras neste momento." $\mathrm{O}$ expresidente tem se dedicado também aos livros. Acabou de ler uma obra que recomenda: "Galileu" ("Galilée", ed. Plon), do físico Claude Allègre, ex-ministro da Educação, da Pesquisa e da Tecnologia. FHC pretende voltar à leitura dos clássicos políticos, para um livro que está escrevendo, no qual vai relacionar as idéias de pensadores como Maquiavel a acontecimentos brasileiros e experiências que viveu. (Folha de S. Paulo, 2003) $)^{5}$

Neste enunciado, constrói-se uma imagem do presidente bastante emblemática de sua caracterização como intelectual e leitor, para quem a leitura compõe um estilo de vida. É sensível o paralelismo que se estabelece entre a prática de leitura do presidente e outras atividades culturais de prestígio, como a frequentação de exposições de arte, viagens internacionais, autoria de livros, e a comportamentos de uma elite econômica, como viagem a Paris. Ao enumerá-las, sequencialmente, "exposições de arte, leituras e compras de supermercado" e ao indicá-las no plural reforça-se esse paralelismo e produz-se o efeito de se tratar de algo que se faz repetidas vezes. Esses dois efeitos (o da equivalência dessas práticas e o da sua

\footnotetext{
${ }^{4}$ A fotografia oficial da presidência, do segundo mandato de FHC, feita por Fernando Gurgel (disponível em: http://gq.globo.com/Prazeres/Poder/noticia/2014/05/todos-os-retratos-dapresidencia.html), assemelha-se bastante à do presidente francês François Mitterrand, feita por Gisèle Freund, em $1981 . \quad$ Disponível em: $<$ https://dnbhistoiredesarts.wordpress.com/2011/08/18/francois-mitterrand-gisele-freund/>.

${ }^{5}$ Alcino Leite Neto. Em Paris, FHC lê e faz compras no mercado. In: Folha de S. Paulo, Seção: Ilustrada, 10/01/2003. Disponível em: <http://www1.folha.uol.com.br/fsp/brasil/fc1001200311.htm>.
} 
EID\&A - Revista Eletrônica de Estudos Integrados em Discurso e Argumentação, Ilhéus, n. 16 esp. "Discurso e argumentação na política latino-americana, set.2018.

frequência) contribuem para produzir a ideia da habitualidade e até banalidade da leitura, o que pode ser depreendido também da relação de pelo menos dois outros indícios.

O primeiro diz respeito ao anúncio de que essas atividades se realizam quando o presidente se encontra "de férias em Paris", período em que se faz prioritariamente o que se gosta de fazer, o que se faz por prazer e por isso sempre que se pode. O segundo diz respeito às escolhas linguísticas e argumentativas para especificar as exposições frequentadas e os textos lidos. A regularidade com que se empreende essas atividades é aludida em especial de duas maneiras distintas em duas passagens desse enunciado: 1) "Em menos de uma semana, FHC visitou duas exposições: do francês Francis Picabia e do italiano Amadeo Modigliani."; 2) a) "Lê os jornais "Le Figaro", “Le Monde” e "International Herald Tribune", além de um clipping de notícias brasileiras enviado pela embaixada. [...]; b) Acabou de ler uma obra que recomenda: "Galileu" [...]; c) FHC pretende voltar à leitura dos clássicos políticos, para um livro que está escrevendo [...]".

Na primeira, o emprego de uma locução adverbial com valor temporal, "em menos de uma semana", não apenas define um período de tempo que localiza a realização da ação, mas também demonstra uma apreciação do enunciador na ênfase dada a sua quantificação "em menos de", qualificando-o positivamente como pouco tempo para a realização da ação de visitar duas exposições de arte. Isso reforça a ideia de gosto, de disposição e de interesse da parte de FHC, mas também a da excepcionalidade dessa ação. A orientação argumentativa empregada pelo enunciador reforça não apenas a adequação da prática do presidente àquela própria do estilo de vida de intelectuais, como também dá destaque para o que pode ser considerado um traço pessoal ${ }^{6}$.

$\mathrm{Na}$ segunda, os recursos linguísticos mobilizados para marcar essa iterabilidade são outros: pelo emprego de certos tempos verbais, e por sua organização temporal sequencial. Em a) emprega-se o verbo 'ler', flexionado na $1^{\text {a }}$ pessoa do presente do indicativo, cujo efeito semântico produzido é um pouco diferente do sentido mais comum que lhe é conferido. Aqui, essa escolha do enunciador indicia uma sua apreciação, ao indicar que se trata de

\footnotetext{
${ }^{6}$ Essa orientação argumentativa responde em certa medida ao imaginário que se constrói acerca do 'habitus de classe' que, segundo Bourdieu (2007), corresponde a um sistema de esquemas durável, social e historicamente constituído, adquirido pelas experiências práticas do indivíduo, em especial, pela transmissão familiar, atuando como uma matriz cultural de percepções, de apreciações e de ações que predispõe os sujeitos a fazerem suas escolhas, mas de modo tal como se elas lhes fossem exclusivamente individuais e espontâneas.
} 
EID\&A - Revista Eletrônica de Estudos Integrados em Discurso e Argumentação, Ilhéus, n. 16 esp. "Discurso e argumentação na política latino-americana, set.2018.

uma ação constante, diária, frequente. Esse efeito torna-se mais tangível pela relação com os complementos verbais, a saber, 'jornais' e 'clipping de notícias', que são gêneros voltados para um consumo cotidiano. Em b) é empregada uma perífrase verbal "acabou de ler", que do ponto de vista temporal indica um passado próximo, e do ponto de vista aspectual indica algo que foi finalizado bastante recentemente em relação ao momento em que se lhe enuncia. Nessa asseveração, é interessante observar, na sequência do período, a oração subordinada adverbial consecutiva "acabou de ler / uma obra que recomenda". Essa construção, por sua estrutura sintática, mas sobretudo por seu papel argumentativo, contribui para a produção do efeito de veridicção da $1^{\text {a }}$ ação realizada: ele leu e tanto o fez que recomenda a leitura. Em c) emprega-se a construção perifrástica "pretende voltar", cujo verbo modal "pretende" implica uma noção de futuro, de ação a ser realizada, ainda que do ponto de vista de sua flexão, ele se inscreva no presente do indicativo. Em sua função modal, ele não apenas compreende essa projeção no tempo, como também reserva semanticamente uma intenção, um compromisso. Em consonância com o verbo principal "voltar" no sentido de retomar e repetir algo já feito, vemos aqui construída argumentativamente uma das ações prototípicas do leitor ideal, a releitura, em especial em relação a certos campos, como o acadêmico, e em relação a certas obras, como os clássicos, consideradas de conhecimento mais relevante, assim como estruturalmente mais complexas. A própria alusão à releitura contribui, desse modo, para a reiteração dos efeitos de frequência e regularidade explorados por meio das outras formas linguísticas. Assim como no emprego desses tempos verbais, os efeitos de constância e de habitualidade da ação se observam ainda por sua organização em uma sequência temporal e pela operação argumentativa que os encadeia. Passa-se do 'presente iterativo', pelo 'pretérito perfeito', até o presente com valor de 'projeção de ação futura', corroborando se tratar de ação que se fez, se faz e se fará ainda.

Além dessas representações que remontam ao discurso dominante sobre a leitura (frequência, regularidade, espontaneidade na leitura e releitura), se manifestam ainda nesse texto analisado a indicação de: a) simultaneidade de leitura de diferentes textos; b) legitimidade e prestígio do 'tipo' de texto que se lê. A prática de se ler simultaneamente diferentes textos, de gêneros editoriais distintos para várias finalidades (Lê os jornais "Le Figaro", "Le Monde" e "International Herald Tribune" / Acabou de ler uma obra que recomenda: "Galileu") é também um traço do perfil leitor ideal, de modo 
EID\&A - Revista Eletrônica de Estudos Integrados em Discurso e Argumentação, Ilhéus, n. 16 esp. "Discurso e argumentação na política latino-americana, set.2018.

geral, e do perfil leitor do intelectual, de modo específico. Isso caracteriza não apenas um interesse mais ampliado pelas coisas a saber, como também pressupõe a capacidade de desenvolver diferentes técnicas de leitura, a intensiva e extensiva $a^{7}$ por exemplo. A enumeração de vários títulos de jornais tradicionais e de alcance mundial, de título de livro recém lido, assim como o anúncio de obras que se lerá, não deixa dúvida quanto a apresentação dessa característica de leitura mais extensiva (ler vários textos, simultânea e sequencialmente, com objetivos e formas de engajamento variados), assim como permite pressupor, ao menos no que concerne à volta aos clássicos políticos, a prática de uma leitura mais intensiva.

Tamanha é a naturalidade e frequência dessa sua representação nos textos da mídia e a 'coincidência' de suas práticas com aquelas do leitor fantasmático de que fala Bayard (2007), que mesmo em textos que lhe são críticos, ainda assim, ele é retratado como leitor. Isso demonstra um aspecto do funcionamento discursivo dos consensos: a partilha de um mesmo discurso sobre a leitura e sobre aspectos do perfil leitor, independentemente da diferença de posicionamento ideológico de seus enunciadores. A ubiquidade dessa sua representação sempre cercado de livros é o mote, por exemplo, de uma piada do humorista José Simão para prenunciar qual seria a função exercida pelo então presidente após o final de seu mandato:

Entendi, é uma agência de turismo com uma estante de livros! Sendo que o único livro que o FHC lê atualmente é o talão do Bradesco! Rarará! (Folha de S. Paulo, 2002) ${ }^{8}$

Articula-se, nessa piada, a referência a três críticas dirigidas ao presidente: uma que lhe valeu a pecha de "Viajando Henrique Cardoso", dadas as sucessivas viagens internacionais que realizou ao longo de seus dois mandatos; a outra, relativa às atribuídas vantagens que o grupo Bradesco obteve durante seu governo, como a aquisição de ações da Vale por valor inferior ao de mercado, depois de ela própria, por meio de um consultor, ter

\footnotetext{
7 Segundo a tese de Rolf Engelsing, na segunda metade do século XIX, ocorre uma revolução da leitura: a passagem da leitura 'intensiva' para a leitura 'extensiva', de uma relação mais cerimoniosa e sacralizada com o texto e com os raros livros de que se dispunha, que se liam lentamente, de forma atenta e repetidas vezes, para uma relação mais laica, mais voraz, mais superficial, dado o interesse de se ler o maior número e variedade de textos, um após o outro ou mais de um livro ao mesmo tempo. Mais do que uma ou outra, o discurso sobre a leitura contemporâneo privilegia, como forma ideal de leitura, a capacidade leitora de alternar essas duas práticas, segundo os textos, contextos e objetivos.

8 José Simão. Buemba! Buemba!. In: Folha de S. Paulo, Seção Ilustrada, 20/11/2002. Disponível em: http://www1.folha.uol.com.br/fsp/ilustrad/fq2011200203.htm.
} 
EID\&A - Revista Eletrônica de Estudos Integrados em Discurso e Argumentação, Ilhéus, n. 16 esp. "Discurso e argumentação na política latino-americana, set.2018.

participado da montagem do edital que definiu as regras da venda; e a terceira, a crítica da exploração de sua imagem pública como um intelectual sempre às voltas com livros. A ironia em relação a esse terceiro aspecto consiste em desvelar a insistência desse protocolo de representação do presidente, retratado constantemente como leitor (agência de Turismo com uma estante de livros) e, para isso, articula uma referência non-sense: "o único livro lido é um talão de cheques". Um talão de cheques, embora apresente certas propriedades físicas que genericamente possam relacioná-lo à forma de um livro (ser impresso, ser encadernado, conter páginas, um certo texto) não corresponde a nenhum dos objetos de prestígio ou que exigiriam competências de leitura para além da mera decodificação. $O$ enunciador explora, nessa construção derrisória, a imagem geral que se compartilha do que é ser leitor (ler muito, ler sempre, ler textos de prestígio) produzindo em relação a ela, uma caricatura, a partir do exagero e de certa subversão de suas características: do ponto de vista da quantidade - ao invés de ser apresentado como quem lê muito, afirma-se que ele tem lido apenas um e um único 'livro'; quanto ao tipo de texto - ao invés de ser apresentado como quem lê livros, ele "lê" um talão do Bradesco, que além de ter outra função entre os objetos de escrita alude à relação condenável entre o presidente, agente público, e o sistema financeiro privado. $\mathrm{Na}$ formulação da piada explora-se derrisoriamente essa ostentação sistemática da representação como leitor de FHC. Ela retoma esse 'já sabido' (ele é leitor e é mostrado como tal) e o critica em sua iteração exagerada e em sua regularidade protocolar. No entanto, ainda que de modo crítico, é como leitor que esse, entre outros textos, apresenta o presidente.

\section{Lula, o 'não- leitor'}

Com o aumento progressivo de sua visibilidade ${ }^{9}$, as possibilidades de vitória de Luiz Inácio Lula da Silva nas disputas eleitorais de que participou sempre foram expressivas. Entre as várias características de seu perfil que sistematicamente foram exploradas em sua apresentação ao público, seu 'capital cultural' foi frequentemente evocado por seus adversários, assim

\footnotetext{
${ }^{9}$ Isso se deu por sua atuação como uma das principais lideranças nas grandes greves de trabalhadores da década de 70, em São Paulo, durante a ditadura militar; por sua participação na criação do Partido dos Trabalhadores, em 1980; e por sua eleição como deputado federal mais bem votado até então do estado de São Paulo, fatos que contaram com significativa, embora relativa, divulgação midiática.
} 
EID\&A - Revista Eletrônica de Estudos Integrados em Discurso e Argumentação, Ilhéus, n. 16 esp. "Discurso e argumentação na política latino-americana, set.2018.

como nos textos da mídia tradicional e depois, com a expansão das mídias digitais, nos textos das redes sociais. Em grande parte das ocorrências, e em comparação aos demais candidatos e os que presidiram a República até então, a alusão a seu 'capital cultural' se fez prioritariamente de maneira disfórica.

O Lula é um homem primitivo e não tem condições de governar. (Veja, 1989) ${ }^{10}$

Lula, demonstração viva do fracasso do Mobral, [...]. Mas Lula, em si, se eleito presidente, afugentaria o capital nacional e possivelmente todo mundo que produz acima do braçal... (O Estado de S. Paulo, 1994) ${ }^{11}$

Não posso continuar apoiando um candidato que não vai ao teatro... (Folha de S. Paulo, 1994) $)^{12}$

A desqualificação de Lula em relação a seu 'capital cultural' se apoia no pressuposto naturalizado entre nós da necessidade de se dispor de certos requisitos culturais considerados essenciais para o exercício da presidência, tanto em seu aspecto administrativo (não tem condições de governar; afugentaria o capital) quanto em seu aspecto simbólico (é um homem primitivo; não vai ao teatro). Tamanha a frequência de afirmação dessa discrepância de seu perfil em relação ao cargo, que o espectro ideológico desse discurso se estende até mesmo sobre o que dizem enunciadores cujos posicionamentos ideológicos seriam antes favoráveis ao presidente:

Ao terminar uma reunião com empresários de Marília, o candidato foi abordado por um eleitor. "Lula, minha mulher tem razão: ela sempre diz que você é o semi-analfabeto mais inteligente que ela já viu". O "elogio" constrangeu o candidato. (Folha de S. Paulo, 1994) ) $^{13}$

Nesse processo de desqualificação - relativamente mais sutil e modalizado quando empreendido nos textos da mídia tradicional e nos gêneros de responsabilidade dessas instituições, e relativamente mais agressivo, incisivo e calunioso em mídias sociais como blogs - é significativa a produção e repercussão de uma série de textos que representam o presidente

\footnotetext{
${ }^{10}$ Declaração do deputado Ricardo Fiuza (PFL-PE) no texto No moedor de carne. Lula cresce e seus adversários preparam a carnificina para a reta final. In: Veja, ed. 1103, ano 22 n. 43, 01/11/1989. Disponível em: <https://acervo.veja.abril.com.br/\#/edition/1103?page=48\&section=1\&word=Lula >

${ }^{11}$ Paulo Francis. Diário da Corte - O mundo em 1994. In: O Estado de S. Paulo, Editorial: Espaço Aberto, p. 97. 02/01/1994. Disponível em: <http://acervo.estadao.com.br/pagina/\#!/19940102-36600nac-0097-cd2-d14-not>.

12 A. P. Ex-garoto-propaganda de Lula adere a tucanos. In: O Estado de S. Paulo, Editorial, Política/Governo, 14/07/2001, p. 07.

${ }^{13}$ Carlos Eduardo Alves. Peso do preconceito surpreende Lula. In: Folha de S. Paulo. Caderno

Especial, 02/10/1994. Disponível em:

<http://www1.folha.uol.com.br/fsp/1994/10/02/caderno_especial/13.html>.
} 
EID\&A - Revista Eletrônica de Estudos Integrados em Discurso e Argumentação, Ilhéus, n. 16 esp. "Discurso e argumentação na política latino-americana, set.2018.

Lula como não-leitor. Nas mídias impressas tradicionais isso se constrói pela quase total ausência de imagens equivalentes àquelas de $\mathrm{FHC}$ em bibliotecas, em frente a estantes de livros, com algum livro em mão ou fazendo referência a algum livro lido. Nos raros textos em que se apresenta Lula com um livro ou com um jornal, imediatamente, e em confluência com essa representação predominante como não-leitor, é a referencialidade e a veridicidade desse tipo de imagem o que é relativizado, questionado ou ironizado.

Nas mídias digitais, essa representação como não-leitor se faz basicamente pela negação de sua condição leitora por meio do humor, e de duas maneiras: na sua forma mais básica (nega-se a competência decodificadora); e na sua forma mais sofisticada (nega-se o hábito letrado). A forma mais frequente de representá-lo como não-leitor é a do primeiro tipo. É flagrante o tom jocoso e sarcástico adotado em vários textos, o que se indicia na escolha dos próprios gêneros discursivos: são charges, fotomontagens, videomontagens, especialmente publicados em blogs pessoais ou de colunistas de revistas e jornais. O efeito derrisório neles explorado apoia-se em um repertório de imagens conhecidas e interpretadas em conformidade com uma dada memória discursiva diligentemente reforçada e de longa duração, acerca do analfabetismo. Vários desses textos revisitam, em sua formulação, um dos gestos prototípicos que denunciam a condição de analfabeto: Lula segura um livro em posição inversa, de cabeça para baixo. Esse tema é reiterado a esmo nas representações de Lula como leitor. Ele faz série com outros gestos também bastante prototípicos de caracterização das impossibilidades ou dificuldades enfrentadas por analfabetos ou semianalfabetos: apenas saber 'ler' figuras, ler de forma silabada, com dificuldade e demoradamente, fingir ler sem poder fazê-lo efetivamente.

Ao explorarem o humor na caracterização do presidente como nãoleitor, esses textos visam produzir empatia e identificação quanto ao ponto de vista que assumem. A certeza da distância em que se encontram o enunciador (e aqueles que com ele riem) daquele(s) que é (são) o tema de seu riso, advêm de um longo processo de 'apagamento' e 'esquecimento' (próprios do funcionamento ideológico que norteia toda e qualquer enunciação), que instaura e perpetua a naturalização de certas hierarquias culturais que, por sua vez, silenciam e tornam invisíveis o ultraje dos representados e o preconceito dos que assim os representam. 
EID\&A - Revista Eletrônica de Estudos Integrados em Discurso e Argumentação, Ilhéus, n. 16 esp. "Discurso e argumentação na política latino-americana, set.2018.

Os instrumentos para a manutenção desses estigmas e sua naturalização são múltiplos, comuns e aparentemente inofensivos, como é o caso dessas 'brincadeiras' sob a forma de charges, fotomontagens e videomontagens. Por se tratar de uma piada, por parecer ser também uma 'crítica política', ou menos que isso, por parecer ser apenas uma 'crítica a um político específico' e por aparentar ser no máximo apenas uma amplificação de algo real (afinal, Lula não é bacharel, tal como os outros presidentes do Brasil), a dimensão trágica do estigma e preconceituosa daqueles que reatualizam a caricatura do analfabeto, são minoradas e se tornam quase imperceptíveis como tal.

Nos vários textos que repercutem alguma referência que o presidente fez a livros que leu ou estaria lendo, ou que simplesmente ganhou de presente e com eles posou para fotos, há uma regularidade, a denegação da leitura como hábito letrado.

\footnotetext{
Lula publica foto irônica no twitter e agita a rede:

O ex-presidente Luiz Inácio Lula da Silva parou nos trending topics do Twitter após uma postagem um tanto inusitada: posou para foto lendo o livro de Leonardo Sakamoto, intitulado O Que Aprendi Sendo Xingado na Internet. E é claro, que a postagem polemizou e os internautas não deixaram por menos. Acompanhe alguns dos comentários que movimentaram a conta do Instituto Lula no Twitter:

1- Será que o Lula está entendendo o que está lendo?

2- Hahahaha... foto do lula lendo é a coisa mais fake q já vi hahahahahaha 3-É só de figurinhas? (Hora Brasil, 2016) ${ }^{14}$
}

Nesse texto, a afirmação de que a foto é irônica é bastante curiosa, porque em sua estrutura ela é ambígua de modo a não especificar onde residiria seu traço irônico: no fato de Lula ler este livro? ou simplesmente no fato de Lula ler?

A ambiguidade quanto ao escopo da ironia é prontamente desfeita quando, na composição do texto, são incorporados os comentários gerados pela publicação da foto no twitter. Neles não há menção ao livro ou a seu conteúdo. É consenso nesses comentários interpretar como irônico o fato de Lula ler, e para isso retomam todos os lugares-comuns acerca do analfabetismo: se lê, não entende; finge ler (é fake); só consegue ler imagens. A ironia a que se refere o título desse texto só pode recair, portanto, sobre o fato de Lula ler. Isso também se desambiguiza quando o enunciador qualifica a postagem como "um tanto inusitada" e conclui valendo-se de uma forma

${ }^{14}$ Site Hora Brasil. Seção Brasil. Notícias. Lula publica foto irônica no twitter e agita a rede. 13/06/2016. Disponível em <http://www.horabrasil.com.br/9803/lula-ironia-publicar-foto-twitter/>. 
EID\&A - Revista Eletrônica de Estudos Integrados em Discurso e Argumentação, Ilhéus, n. 16 esp. "Discurso e argumentação na política latino-americana, set.2018.

assertiva "E é claro... que a postagem polemizou e os internautas não deixaram por menos". O inesperado, aquilo que é novidade ou que raramente acontece, diz respeito a Lula ter sido fotografado "lendo o livro". O já-sabido e asseverado pelo enunciador por meio da expressão "E é claro" é uma das formas linguísticas que simbolizam essa condição de lugar-comum de sua apresentação como não-leitor e que visa a produção do efeito de "obviedade" e "naturalidade" de assim concebê-lo.

Grande parte das representações de Lula como não-leitor se apoia na estratégia de comparação de seu perfil, seja com seus eleitores (que são descritos como não alfabetizados e representados como não-leitores), seja com aquele dos perfis leitores de seu antecessor na presidência, FHC, e de sua sucessora, Dilma. Na comparação com ambos, Lula é o avesso do ideal de leitor.

\section{Dilma, leitora... no feminino}

Durante sua atuação como ministra (de 2003 a 2010) e ao longo de sua campanha para a presidência (2010) quase nada se falou a seu respeito como leitora nos principais jornais e revistas de circulação nacional ${ }^{15}$. As primeiras referências ocorrem nas tradicionais matérias pós-eleição que visam apresentar o perfil dos eleitos. Ela é, então, descrita com as características típicas de quem, oriunda de classe média alta, teve acesso e dispõe de capital cultural de prestígio: fez aulas de piano e francês, estudou em escola particular e tradicional, cursou ensino superior, gosta e tem o hábito de ler, de ver filmes, de ir à ópera etc. Embora apresente um histórico de educação formal similar ao de FHC e seja descrita por seus amigos como uma leitora contumaz, as referências a suas práticas leitoras são bem menos frequentes que aquelas a respeito deste, e quando feitas, são em sua maioria derrisórias, tal como ocorre com Lula.

Essa dimensão cultural do perfil de Dilma pode não ter sido explorada nas duas campanhas eleitorais de que participou em função de não representar característica distintiva daquelas pressupostamente também gozadas por seus principais adversários políticos nas duas eleições que

\footnotetext{
${ }^{15}$ Em Curcino (2016) analisamos a repercussão de uma das raras referências a Dilma como leitora antes das eleições de 2010, uma videomontagem na qual se explora derrisoriamente sua capacidade de leitura.
} 
EID\&A - Revista Eletrônica de Estudos Integrados em Discurso e Argumentação, Ilhéus, n. 16 esp. "Discurso e argumentação na política latino-americana, set.2018.

disputou (contra José Serra, em 2010, e contra Aécio Neves, em 2014), e dos quais quase nada se disse em relação aos seus hábitos e gostos letrados.

Depois de eleita, desse silêncio da mídia passa-se a eventuais explorações comparativas de seu perfil cultural, não com seus opositores, nem com FHC, mas sempre com seu antecessor, o presidente Lula. Às vezes na comparação se exploram suas diferenças de perfil quanto à leitura (ela é leitora, Lula não), às vezes suas semelhanças (se leem, não leem bem e/ou não entendem) mantendo, no entanto, uma mesma lógica argumentativa: seja para qualificar ou desqualificar o perfil leitor de Dilma, a comparação com Lula sempre o desqualifica.

Brasília tem dificuldade de se adaptar à troca de um presidente que 'tocava de ouvido' por uma que lê todas as notas da partitura. O que para Luiz Inácio Lula da Silva era intuição, para Dilma Rousseff é um processo de mascar detalhes até chegar à decisão [...] oito anos atrás uma das perguntas típicas quando Lula assumiu a presidência era: "Quantas páginas você acha que ele lê por dia?". A crítica embutida era que o presidente não sabia o que assinava. (O Estado de $\mathrm{S}$. Paulo, 2011) ${ }^{16}$.

O ex-presidente Luiz Inácio Lula da Silva recusava-se a ler o calhamaço antes dos encontros. Ele pedia um resumo do que era importante a seu chanceler, Celso Amorim, e mandava distribuir a papelada "a quem não tivesse nada para fazer". A presidente Dilma Rousseff, ao contrário, lê tudo. Mas não gosta. E reclama, quase sempre. (O Estado de S. Paulo, 2014)

Antes leitora contumaz da imprensa, ela já não lê mais os jornais brasileiros como fazia todas as manhãs na hora do café. Vez ou outra, até navega por notícias internacionais. Mas só. Com bastante frequência, é algum assessor que Ihe chama a atenção para algum assunto específico na mídia. Assim, Dilma repete o hábito de seu antecessor, Luiz Inácio Lula da Silva, que considerava que a imprensa só trazia más notícias e achava melhor ignorá-las. (Folha de $\mathrm{S}$. Paulo, 2015) ${ }^{18}$

Assim, quando se mencionam as competências leitoras de Dilma, em grande parte dos textos isso é feito a partir da comparação com Lula. O que se

\footnotetext{
${ }^{16} \mathrm{~J}$. R. Toledo. Entrou a meio-campo e carrega a bola sozinha até o ataque. In: O Estado de S. Paulo, Seção Nacional, Caderno A4, 07/08/2011. Disponível em: <http://acervo.estadao.com.br/pagina/\#!/20110807-43027-spo-4-pol-a4not/busca/anulados+controle+total>.

${ }^{17}$ Lisandra Paraguassu. Ministro muda forma de relatório criticado por presidentes. In: O Estado de S. Paulo, Seção Política. $\quad 02 / 01 / 2014 . \quad$ Disponível em $<$ http://politica.estadao.com.br/noticias/eleicoes,ministro-muda-forma-de-relatorio-criticado-porpresidentes-imp-,1114213>.

${ }^{18}$ Natuza Nery. Em meio a crise, Dilma deixa de ler jornais e tenta exibir autocontrole. In: Folha de S. Paulo, Seção Poder, O impeachment, 09/08/2015. Disponível em: $<$ http://www1.folha.uol.com.br/poder/2015/08/1666364-auxiliares-veem-dilma-em-fase-de-negacaoda-realidade.shtml>.
} 
EID\&A - Revista Eletrônica de Estudos Integrados em Discurso e Argumentação, Ilhéus, n. 16 esp. "Discurso e argumentação na política latino-americana, set.2018.

diz dele nesses casos não varia muito: ele não lê, não gosta de ler, recusa-se a ler, acha que ler é coisa de quem não tem o que fazer. Quanto a ela, à primeira vista, as referências parecem ser mais descritivas. No entanto, são frequentadas por uma ambiguidade constitutiva que progressivamente assume um tom disfórico:

Detalhista, Dilma lê linha por linha de todos os projetos e manda refazê-los várias vezes. Os vazamentos de informações, principalmente de pedaços de propostas que ela não analisou, irritam a presidente, que não suporta disputas veladas entre auxiliares - ela está convencida de que muitos desses vazamentos têm por trás esse objetivo, sobretudo na equipe econômica. Beira o ódio presidencial a quebra da regra que não permite que ministros comentem temas de pastas alheias. Dilma ficou furiosa, por exemplo, com o ministro do Desenvolvimento, Indústria e Comércio Exterior, Fernando Pimentel, depois de ler nos jornais uma parte do projeto da política industrial, o Plano Brasil Maior, só divulgado no início da semana passada. Na solenidade de lançamento, no Planalto, a presidente anunciou o projeto como seu, e não do ministério, o que ofuscou a imagem de Pimentel. Em quase todos os ministérios há projetos aguardando o desembargo presidencial. (O Estado de S. Paulo, 2011) ${ }^{19}$

Dadas as relações parafrásticas internas e externas que determinam os sentidos do que é enunciado em um texto, segundo um princípio da Análise de discurso, ao ser descrita como 'detalhista' no modo como lê, essa qualificação faz série com outras. Ela é também apresentada como mandona e dominadora (manda refazer várias vezes), irritadiça (os vazamentos irritam a presidente), desconfiada (convencida de que muitos vazamentos são propositais), irascível (beira o ódio, fica furiosa), centralizadora (já que apresentou o projeto como seu, e não como do ministério) e vaidosa (já que ofuscou a imagem de Pimentel). Logo, o caráter supostamente eufórico que poderia se encontrar na descrição dessa sua prática leitora 'detalhista' - que poderia ser sinônimo de leitura cuidadosa e atenta, em outros contextos e textos - é anulado e negativado, porque se encadeia com formas de descrição de personalidade que indiciam antes um perfil psicológico obsessivo e autoritário $^{20}$.

Suas características como leitora ("lê todas as notas/masca detalhes", "lê os jornais", "lê tudo", "leitora contumaz da imprensa"), embora

\footnotetext{
${ }^{19} \mathrm{~J}$. Domingos; V. Mendes; D. Madueno. Com projetos na gaveta, ministros são anulados por controle total de Dilma. In: O Estado de S. Paulo, Seção Nacional, Caderno A4, 07/08/2011. Disponível em: $<$ http://acervo.estadao.com.br/pagina/\#!/20110807-43027-spo-4-pol-a4not/busca/anulados+controle+total>.

${ }^{20}$ Não são raros os exemplos na mídia impressa em que ela é descrita com características que recuperam o estereótipo da mulher histérica (nervosa, caprichosa, de comportamento desproporcional, dissimulada), atualizando assim esse estigma antigo e frequente de viés sexista.
} 
EID\&A - Revista Eletrônica de Estudos Integrados em Discurso e Argumentação, Ilhéus, n. 16 esp. "Discurso e argumentação na política latino-americana, set.2018.

respondam às características que se atribui ao bom leitor (ler muito, sempre, em detalhe, ler os textos que importam/valem a pena/são necessários para sua atuação), são obliquamente apresentadas mais como um traço de uma personalidade problemática do que uma qualidade a se dar relevo. Isso se observa em vários textos:

Ela quer ser chamada de presidenta; enérgica e detalhista, encasqueta com metas, mas não esconde o lado zen: faz meditação, aprecia óperas, devora livros e se diverte com os seus dois cachorros. [...] Literata. Na prática, ela lê tudo o que cai em suas mãos: de poesias de Adélia Prado a Fernando Pessoa; de romances de Machado de Assis a Honoré de Balzac. [...] "Uma coisa que me impressiona muito é que a Dilma cita trechos de obras literárias de cabeça", conta o novo ministro da Justiça, José Eduardo Martins Cardozo. "Eu também sou rato de biblioteca, mas, como ela, nunca vi igual." [...] "A gente ia a passeatas de protesto e lia muito (Régis) Debray e Che Guevara", lembra o exprefeito de Belo Horizonte Fernando Pimentel (PT), agora ministro do Desenvolvimento, Indústria e Comércio Exterior do novo governo. [...] "Ela tinha 22 anos, usava lentes grossas, estudava macroeconomia e lia sem parar", conta a jornalista Rose Nogueira, presidente do Grupo Tortura Nunca Mais-SP, que conviveu com Dilma no presídio. (O Estado de S. Paulo, 2011) ${ }^{21}$

Brian Winter perfila: "O próximo governo do Brasil: a ascensão dos nerds", na Reuteurs. Afirma que "Dilma está montando um gabinete à sua imagem: um grupo de tecnocratas dados à leitura que, como ela, subiram ao poder não por carisma ou ligações políticas, mas por sua habilidade em mastigar números e fazer as coisas acontecerem". Em suma "no sentido mais bondoso, um governo de nerds". (Folha de S. Paulo, 2010) $)^{22}$

Essas menções ao modo como Dilma "devora livros" ("lê tudo", "lê muito", "lê sem parar", "rata de biblioteca", "tecnocrata dada à leitura", "nerd"), embora atribuídas às vezes àqueles que lhe são próximos e empregadas por eles para descrevê-la de modo eufórico como leitora, convertem-se progressivamente nesses textos em representações ambíguas em função do modo como os enunciadores empregam essas citações e as articulam a diferentes características de sua prática e de seu perfil psicológico, em textos cujo tom reorientam a significação desse atributo em seu valor positivo.

Mesmo lendo de modo rigoroso os textos técnicos que sua profissão exige, ou lendo espontaneamente obras consagradas, em momentos de descanso, por gosto e para sua formação, em sua descrição como leitora

\footnotetext{
${ }^{21}$ Vera Rosa. Dilma no poder: novos gostos e costumes. In: O Estado de S. Paulo. Seção Política. 01/01/2011. Disponível em: <http://politica.estadao.com.br/noticias/geral,dilma-no-poder-novosgostos-e-costumes,660714>.

${ }^{22}$ Nelson de Sá. Um governo de nerds. In: Folha de S. Paulo, Caderno Poder, 02/12/2010. Disponível em: <http://acervo.folha.uol.com.br/resultados/?q=nerds\&site=fsp\&periodo=acervo\&x=11\&y=16>.
} 
EID\&A - Revista Eletrônica de Estudos Integrados em Discurso e Argumentação, Ilhéus, n. 16 esp. "Discurso e argumentação na política latino-americana, set.2018.

observa-se sempre uma atenuação ou até mesmo uma inversão do caráter positivo dessas práticas. Essa ambiguidade se encontra em especial nos textos do período do rito formal de seu impeachment, quando as referências a ela como leitora e a suas práticas de leitura se multiplicaram.

Sem tempo, Dilma trocou a leitura frenética de livros pela análise minuciosa de mapas de votação na Câmara. ${ }^{23}$

Desde que foi afastada do cargo de presidente da República, há 73 dias, Dilma foi obrigada a se despir das formalidades de seu antigo gabinete, no terceiro andar do Palácio do Planalto, e transferir seu escritório para a biblioteca do Alvorada [...]. Diante do cenário pouco animador, a petista tenta relaxar. Dedica-se mais à leitura e a séries no Netflix, vícios que conseguiu retomar com mais frequência somente ao ser afastada da Presidência. [...] Quando está inquieta, deixa a biblioteca e vai procurar os assessores nas salas de reuniões que ficam de frente para o jardim da residência oficial. 'Ela procura trabalho, mas não tem muito o que fazer', confidencia um dos visitantes corriqueiros. (Folha de S. Paulo, 2016) ${ }^{24}$

Qualificada como 'frenética' designada como 'um vício', tratada como hábito de 'devorar' livros, nivelada com 'séries do Netflix', designada como 'coisa de nerds', como prática 'para relaxar' diante do fato de não 'ter muito o que fazer', a leitura não é aqui necessariamente apresentada como uma prática exclusiva ou prioritariamente positiva. A biblioteca também não foi retomada em seus traços simbólicos mais eufóricos. A leitura é apresentada como passatempo e a biblioteca como o lugar para se passar o tempo. Os símbolos basicamente eufóricos do livro, da leitura, da biblioteca são tratados nesses textos de modo bastante enviesado como objetos, práticas e espaços frívolos. É possível ver nisso um eco da divisão cultural que ao longo da história destinou diferentes práticas, obras e usos da leitura para homens e para mulheres.

Suas leituras, com finalidades técnica e pragmática para o exercício de sua função, e literárias para entretenimento, embora sejam legítimas e gozem de prestígio em nossa sociedade, são apresentadas de forma menos legitimante do que aquelas que se atribui ao presidente FHC. Depois que ambos deixam a presidência, ele é retratado como quem lê para continuar

\footnotetext{
${ }^{23}$ Vera Rosa. Presidente entra no toma lá, dá cá. In: O Estado de S. Paulo. Seção Política. A5. Domingo, 27/03/2016. Disponível em: <http://acervo.estadao.com.br/pagina/\#!/20160327-44721-nac5-pol-a5-not>.

${ }^{24}$ Marina Dias. Com retorno difícil, Dilma quer 'defender biografia' no Senado. In: Folha de S. Paulo, caderno Poder, Seção O Impeachment, 24/07/2016. Disponível em: <http://www1.folha.uol.com.br/poder/2016/07/1794761-dilma-passa-tempo-com-series-e-livrosenquanto-aguarda-julgamento.shtml $>$.
} 
EID\&A - Revista Eletrônica de Estudos Integrados em Discurso e Argumentação, Ilhéus, n. 16 esp. "Discurso e argumentação na política latino-americana, set.2018.

atuando publicamente, como formador de opinião, como acadêmico, político e escritor. Ela é representada como quem lê para entretenimento, para passar o tempo, ainda que as referências sejam da leitura de clássicos literários. Anula-se, com isso, o prestígio que sua condição leitora poderia lhe outorgar para o exercício da política.

\section{Algumas considerações}

As representações desses políticos em relação à leitura nos colocam diante de valores e de estigmas antigos e duradouros, não restritos ao campo da política. Elas participam, no âmbito simbólico, das distinções sociais mais amplas e perversas que sistematicamente emergem nos textos das velhas e das novas mídias, universalizando e naturalizando essas divisões de classe, de gênero, valendo-se da blindagem do humor ou da crítica de viés político.

Nas diferenças de descrição desses ex-presidentes como leitores ouvimos o eco de "lutas de representação" mais difusas e cotidianas. É o funcionamento discursivo desses 'ecos' sutis, ubíquos e perenes que buscamos melhor compreender em nossa análise dos discursos sobre a leitura - responsáveis pela constância e força de uma série de estigmas que nos ensinam, desde muito cedo, a ser quem devemos ser, segundo limites impostos por nossa história, por nossa origem social e cultural (Bourdieu, 2007). Com os epítetos "leitor ideal", "não-leitor" e "leitora... no feminino", buscamos sintetizar essas divisões em relação às quais não temos, em geral, consciência de seu papel simbólico e de sua envergadura social na etiquetagem dos sujeitos.

De modo geral, FHC e Dilma contaram com uma paleta mais generosa nas cores de representações como leitores, se comparados a Lula, mas nem por isso de maneira equitativa. Mesmo quando se compartilha características do leitor ideal, como é o caso de FHC e Dilma, é possível identificar nesses textos que descrevem seus perfis leitores significativas diferenças de graus de legitimidade, alguns ligados a diferenças de gênero. Tal como foram atribuídas aos homens, nas suas representações como leitores ao longo da história, as leituras de fôlego, de importância e de envergadura intelectual, com finalidades públicas, $\mathrm{FHC}$ contou, mesmo nos textos que the eram exclusiva e incisivamente críticos, com uma representação como homem letrado e erudito com livros como adereço. Tal como foram atribuídas às mulheres as leituras de foro mais íntimo, mais leves, para lazer, prazer e evasão, Dilma foi 
EID\&A - Revista Eletrônica de Estudos Integrados em Discurso e Argumentação, Ilhéus, n. 16 esp. "Discurso e argumentação na política latino-americana, set.2018.

representada como mulher leitora: compulsiva por livros, leitora contumaz de literatura que nas horas 'livres' se recolhia na leitura. No âmbito de suas atividades públicas, num terreno historicamente ocupado por homens, as referências a sua prática leitora afirmam a inadequação de seu modo de ler (já que ela lia em detalhe, sempre e todos os textos). A ausência de menções equivalentes no caso de $\mathrm{FHC}$ pode indiciar que ele lia como era devido na rotina do trabalho presidencial. A construção de sua legitimidade política enfrentou outros estigmas. Nenhum em relação ao 'capital cultural' de prestígio, nenhum em relação a sua imagem como leitor.

Quanto a Lula, grande parte das desqualificações que lhe foram dirigidas se ligam direta ou indiretamente a seu 'capital cultural'. As alusões à leitura são caracterizadas pela intensidade das críticas, assumindo por vezes a forma explícita do preconceito e da injúria. Por isso, a referência a esse tipo de prática específica não deixa dúvida quanto a seu poder simbólico na construção dos perfis sociais em geral, e dos perfis políticos em específico. Não apenas Lula é representado como não-leitor, como também está condenado a não poder sê-lo. Sem o batismo institucional que afiançaria essa competência (o ensino superior, por exemplo), ele desrespeita a tradição hagiográfica cultural da política, daí o caráter sacrílego de seu gesto, que explica as reações imediatas, sob a forma disfórica, quando ele posa para uma foto com um livro ou faz referência à leitura de um título.

Se as condições da atualidade política no Brasil deram relevo à exploração do 'capital cultural', em especial do capital simbólico da leitura, como forma de diferenciação dos perfis dos presidenciáveis, é na longa duração que alguns traços dessa distinção se sustentam, assim como é no seu funcionamento disperso e constante em relação a toda a sociedade que ela se concretiza. Por essa razão, é fundamental que coloquemos sob suspeita os usos que se fazem dessa imagem idílica do leitor ideal e que reconheçamos que a leitura, como prática resultante de certos discursos, exige de nós um compromisso teórico, profissional, ético e político em seu ensino e em sua efetiva democratização, de modo a reconhecermos e polemizarmos com as formas discursivas de perpetuação das hierarquias, que fazem da leitura mais um de seus instrumentos de estigmatização social, e não uma prática potencialmente emancipadora e politicamente democratizante, como ela deve e precisa ser. Com a análise desse e de outros discursos "devemos 
EID\&A - Revista Eletrônica de Estudos Integrados em Discurso e Argumentação, Ilhéus, n. 16 esp. "Discurso e argumentação na política latino-americana, set.2018.

buscar extrair da contingência histórica que nos faz ser o que somos as possibilidades de ruptura e mudança” (FOUCAULT, 2005).

\section{Referências}

BAYARD, Pierre. Como falar dos livros que não lemos? Rio de Janeiro: Objetiva, 2007.

CHARTIER, Roger. A história Cultural - entre práticas e representações. Lisboa: Editora Difel, 1990.

. A aventura do livro: do leitor ao navegador. São Paulo: Ed.UNESP, 1999.

. Uma trajetória intelectual: livros, leituras, literaturas. In: ROCHA, J. C, C. (Org.). A força das representações: história e ficção. Chapecó: Argos, 2011.

COURTINE, Jean-Jacques. O chapéu de Clémentis. In: INDURSKY, F., LEANDRO FERREIRA M. C. (Org.). Os Múltiplos territórios da Análise do Discurso. Porto Alegre: Ed.Sagra Luzzato, 1999.

CURCINO, Luzmara. Discursos hegemônicos sobre a leitura e suas formas de hierarquização dos leitores. In: CURCINO, L.; SARGENTINI, V.; PIOVEZANI, C. (Org.). (In)Subordinações contemporâneas: consensos e resistências nos discursos. São Carlos: EDUFSCar, 2016.

FOUCAULT, Michel. A ordem do discurso - Aula inaugural no Collège de France. São Paulo: Edições Loyola, 1996.

. O Que São as Luzes? In: Ditos e Escritos II: Arqueologia das Ciências e História dos Sistemas de Pensamento. Editora Forense Universitária, 2005.

HÉBRARD, Jean. O autodidatismo exemplar. Como Valentin Jamerey-Duval aprendeu a ler? In: CHARTIER, R. (Org.). Práticas da leitura. São Paulo: Estação Liberdade, 2001.

Forma de citação sugerida:

CURCINO, Luzmara. Imprensa e discursos sobre a leitura: representações dos presidentes FHC, Lula e Dilma como leitores. EID\&A - Revista Eletrônica de Estudos Integrados em Discurso e Argumentação, Ilhéus, n. 16 esp. "Discurso e argumentação na política latino-americana", p. 223-243, set.2018.

Recebido em: 25/07/2018

Aprovado em: $26 / 08 / 2018$ 